\title{
EVALUATION OF SIMVASTATIN EFFICACY ON BONE REGENERATION FOR SOCKET PRESERVATION
}

\author{
Hatim Ahmed Miftah Abu Sheehah ${ }^{* 1}$, Ahmed Mohamed Hosni' ${ }^{2}$, Wael Ahmed EI Mohandes ${ }^{3}$
}

\begin{abstract}
Objective of this study to was to evaluate the efficacy of simvastatin on bone regeneration for socket preservation after tooth extraction radiographically. Subject \& Methods: 20 dental sockets were classified equally in to two groups. Group A: (study group), where 10 tooth sockets were filled gelatin sponge with simvastatin. Group B: (control group), where 10 tooth sockets were filled with gelatin sponge alone. all sockets were then closed with black silk Follow up patients to assess pain, swelling or presence of infection Computed tomographic (CBCT) scanning was performed immediately and after four months to measure the bone height, bone width, and bone density The radiographic measurements were compared and the differences were statistically analyzed. Results: It was found significant increase in density in the study group than the control group, there was a statistically significant difference in mean width in the two groups and there was a statistically non-significant difference in mean height in the two groups. Conclusion: Simvastatin induce bone formation as in this study showing a significant increase in density in the simvastatin group than the control. But cannot preserve alveolar bone height
\end{abstract}

KEYWORDS: Bone regeneration, simvastatin, socket preservation.

\section{INTRODUCTION}

Alveolar ridge resorption is a phenomenon following the extraction of the teeth in an otherwise healthy individual ${ }^{(1)}$. The rate of alveolar ridge resorption after teeth extraction vary between sites and subjects. This may lead to inadequate bone volume and unfavorable ridge architecture for placement of the dental implant ${ }^{(2)}$. The loss of tissue contour occurs mostly during the first 1 to 3 months after tooth extraction ${ }^{(3)}$.

Therefore, alveolar dimensions preservation following tooth extraction is crucial to maintaining adequate bone volume for implants placement and stabilization to obtain optimal esthetic and functional prosthetic results ${ }^{(3)}$. Ridge preservation measures consist of the use of varied bone substitutes, barrier membranes, and biologically active materials and several different surgical methods ${ }^{(4)}$.

The gold standard still considered for grafting procedures is autogenous bone but is associated with several problems including morbidity of the donor site and limitation of the amount of bone that can be harvested ${ }^{(6,7)}$. Until now, there is still no consensus concerning which material or technique is the most effective not only in limiting post extraction resorption but also at the same time in assisting the regeneration of high-quality bone ${ }^{(8)}$.

1. Masters Candidate, Misurata University, Libya

2. Lecturer of oral and maxillofacial, Faculty of Dental Medicine, Boys, Cairo, Al Azhar University

3. Professor, Head of oral and maxillofacial Department, Faculty of Dental Medicine, Boys, Cairo, AL-Azhar University

- Corresponding author: bushiha.dent@gmail.com 
Osteogenesis can be stimulated by applying bone formation stimulating molecules, bone regeneration is a complex process of bone formation similar to normal fracture healing and bone remodeling. The successful bone repair involves three essential components which are osteoinduction, osteogenesis, and the osteoconductive matrix ${ }^{(9,10)}$.

Simvastatin a cholesterol-lowering medication that is used systemically in the osteoporosis treatment due to its ability in bone formation ${ }^{(11)}$. Stimulation of the new bone formation by simvastatin concluded by the increased expression level of bone morphogenetic protein-2 (BMP-2) in bone cells, During bone repair bone morphogenic proteins (BMPs) are essential regulators of osteogenic differentiation. BMP-2 causes multipotent stem cells to differentiate into osteoblast-like cells ${ }^{(12,13)}$.

\section{SUBJECT AND METHODS}

This study was an intervention randomized clinical trial study including 20 dental sockets Patients were selected from Outpatient Clinic of the Department of Oral and Maxillofacial Surgery, Faculty of Dental Medicine, Al-Azhar University. A total sample size of 20 patients (10 patients in each group) were selected. An effect size of 0.56 , at a power (1- $\beta$ error) of 0.8 , using a two-sided hypothesis test, significance level ( $\alpha$ error) 0.05 for data.

For control group, ten patients ranged in age between 18.0-36.0 years with a mean age of $26.80 \pm 7.93$ years and ten patients ranged in age between 18.0-33.0 years with a mean age $25.80 \pm 5.79$ years for the study group.

Good oral hygiene, a willingness to cooperate with the study protocol and follow-up program, patient with hopeless tooth that were indicated for extraction without periapical lesion and patient without any systemic disease that interfere with healing were included. Exclusion criteria include systemic diseases affecting bone metabolism, uncontrolled periodontal diseases that interfere with healing, patients on long-term steroid, and pregnant woman.
Before initiating procedure examination for the tooth to be extracted and neighboring teeth was done and Intraoral periapical radiograph film was taken to evaluate the general condition of the patient bone and anatomical structure.

The procedure was performed under local anesthesia (Articaine HCL 68mg/1.7ml (4\%) Epinephrine $0.017 \mathrm{mg} / 1.7 \mathrm{ml}$ ). All first molars were extracted carefully, with minimal soft tissue reflection and without causing any damage to the underlying alveolar bone. The socket was then gently irrigated with normal saline and hemostasis was achieved.

Immediately after the extraction gelatin sponge mixed with simvastatin (10 mg tablet crushed and mixed with normal saline) was placed in extraction sockets of study group while only gelatin sponge was placed in extraction sockets of control group. Once it is placed, the sockets were closed with black silk to prevent gelatin sponge from getting displaced

Patients were instructed to biting on the gauze for 30-60 minutes, do not spit, rinse, suck (using a straw), smoke, drink carbonated or alcoholic beverages for at least 24 hours, do not brush your teeth on the day of the surgery. Then resume normal home care, gently brushing and flossing. Antibiotics (Biomox $500 \mathrm{mg}$ cap, SEDICO, Egypt) 3 times per day for five days) and analgesics (Brufen** 400mg tab, Abbott) 3 times per day for four days) were prescribed.

Patients were recalled for regular follow up. Complication such pain, swelling, infection, if any, arising out at first post-operative week were recorded. Romexis software (5.0.0) version* cone-beam computed tomographic (CBCT) scanning was performed immediately and after four months to measure the following radiographic parameters bone height, bone width, and bone density.

The study was approved by the oral and maxillofacial surgery scientific Committee and department council, Faculty of Dental Medicine, Boys, Cairo, Al-Azhar University. A signed informed consent was done from every parents prior to beginning the study 
Data were fed to the computer and analyzed using IBM SPSS software package version 20.0. (Armonk, NY: IBM Corp) Qualitative data were described using the number and percent. The Kolmogorov-Smirnov test was used to verify the normality of distribution Quantitative data were described using range (minimum and maximum), mean, standard deviation and median. The significance of the obtained results was judged at the 5\% level.

\section{RESULTS}

According to patients ages was statistically nonsignificant difference between the two groups regarding to the mean of age. Control group had 2 males and 8 females, while study group had the 10 females. There was statistically non-significant difference between gender distributions in the two groups.
According to comparison between the two studied groups in VAS: at the Day of procedure, $2^{\text {nd }}$ day, $5^{\text {th }}$ day and $7^{\text {th }}$ day, there was a statistically non-significant difference in mean VAS in the two groups.

According to comparison between the two studied groups in facial edema $(\mathrm{cm})$ : at the Day of procedure, 2nd day, 5th day and 7th day, there was a statistically non-significant difference in mean facial edema $(\mathrm{cm})$ in the two groups.

According to comparison between the two studied groups in infection: $100.0 \%$ of the patients had no infection in both control and study groups.

According to comparison between the two studied groups in width figure (1): immediately, there was a statistically non-significant difference in mean width in the two groups. After 4 months, there was a statistically significant difference in mean

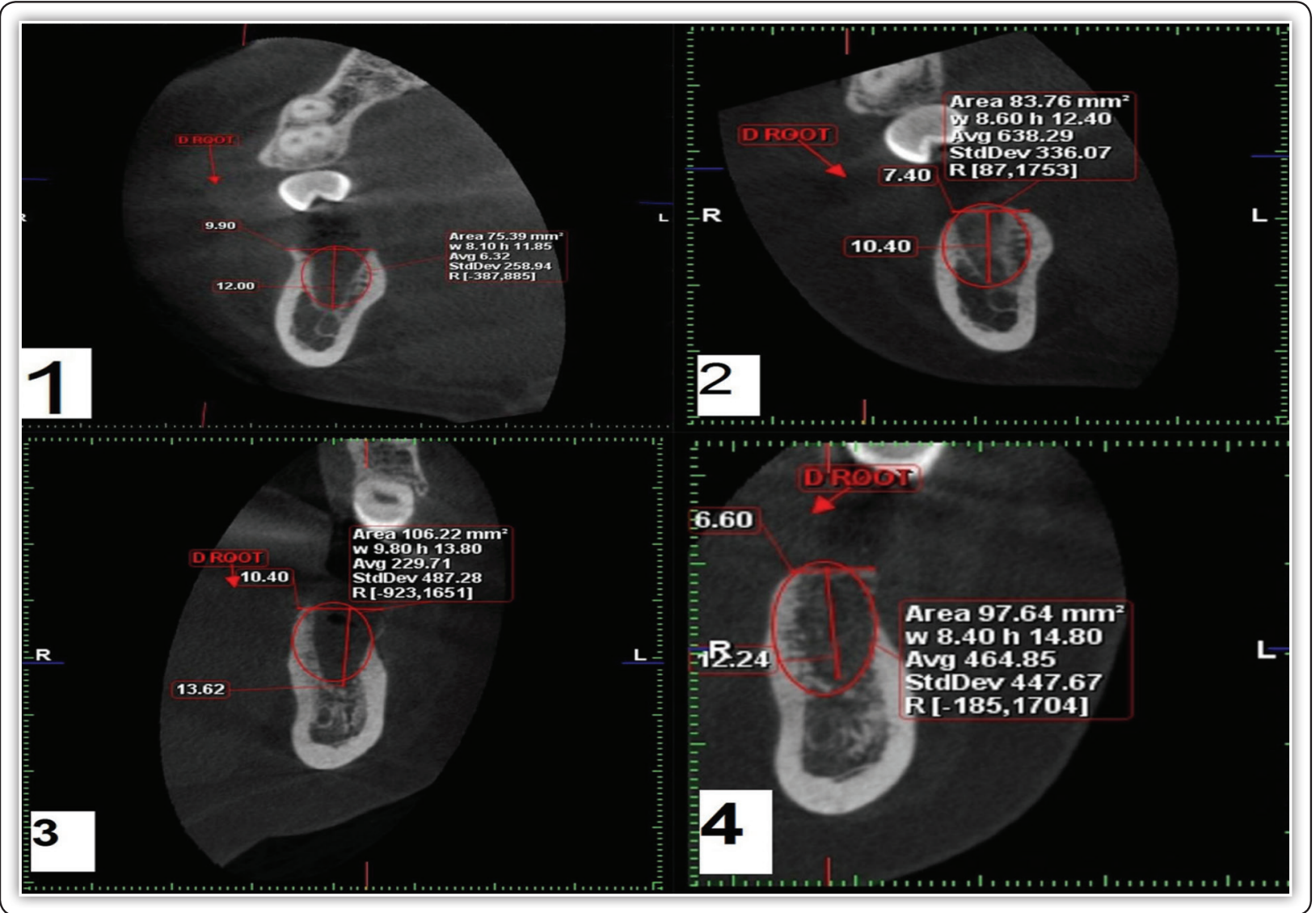

FIG (1) Showing measurement of bone height, density and width, for study group (1) immediately after extraction while (2) after four months, for control group (3) immediately after extraction while (4) after four months 
width in the two groups. Control group showed a significant decrease in width than study group. Percentage of change, there was a statistically a significant difference in mean width change in the two groups. Study group showed a less significant change in width than control group.

TABLE (1) Comparison between the two studied groups according to bone width

\begin{tabular}{|l|c|c|c|c|c|}
\hline \multirow{3}{*}{ Width } & \multicolumn{2}{|c|}{$\begin{array}{c}\text { Control } \\
(\mathbf{n = 1 0})\end{array}$} & \multicolumn{2}{c|}{$\begin{array}{c}\text { Study } \\
(\mathbf{n = 1 0})\end{array}$} & \multirow{2}{*}{ p } \\
\cline { 2 - 5 } & Mean & \pm ISD & Mean & \pm ISD & \\
\hline Immediately & 9.42 & 1.31 & 9.55 & 1.31 & 0.827 \\
\hline 4 months & 5.70 & 1.17 & 8.13 & 0.93 & $<0.001^{*}$ \\
\hline$\%$ of change & -39.48 & 8.93 & -14.41 & 6.67 & $<0.001^{*}$ \\
\hline
\end{tabular}

According to comparison between the two studied groups in height figure (1): Immediately and after 4 months, there was a statistically non-significant difference in mean height in the two groups. Percentage of change, there was a statistically nonsignificant difference in mean height change in the two groups.

TABLE (2): Comparison between the two studied groups according to bone height

\begin{tabular}{|l|c|c|c|c|c|}
\hline \multirow{2}{*}{ Height } & \multicolumn{2}{|c|}{$\begin{array}{c}\text { Control } \\
(\mathbf{n = 1 0})\end{array}$} & \multicolumn{2}{c|}{$\begin{array}{c}\text { Study } \\
(\mathbf{n = 1 0})\end{array}$} & \multirow{2}{*}{$\mathbf{p}$} \\
\cline { 2 - 5 } & Mean & \pm SD & Mean & \pm SD & \\
\hline Immediately & 11.01 & 3.14 & 10.44 & 2.25 & 0.646 \\
\hline 4 months & 9.38 & 3.39 & 9.33 & 2.17 & 0.969 \\
\hline$\%$ of change & -17.52 & 12.22 & -10.83 & 3.07 & 0.315 \\
\hline
\end{tabular}

According to comparison between the two studied groups in density figure (1): immediately, there was a statistically non-significant difference in mean density in the two groups. After 4 months, there was a statistically a significant difference in mean density in the two groups. Study group showed a significant increase in density than control group. Percentage of change, there was a statistically non- significant difference in mean density change in the two groups.

TABLE (3) Comparison between the two studied groups according to bone density

\begin{tabular}{|l|c|c|c|c|c|}
\hline \multirow{3}{*}{ Density } & \multicolumn{2}{|c|}{$\begin{array}{c}\text { Control } \\
(\mathbf{n = 1 0})\end{array}$} & \multicolumn{2}{c|}{$\begin{array}{c}\text { Study } \\
(\mathbf{n = 1 0})\end{array}$} & \multirow{2}{*}{$\mathbf{p}$} \\
\cline { 2 - 5 } & Mean & \pm SD & Mean & \pm SD & \\
\hline Immediately & 242.50 & 90.58 & 294.80 & 149.64 & 0.130 \\
\hline 4 months & 396.40 & 122.87 & 633.50 & 186.20 & $0.002^{*}$ \\
\hline \% of change & $\uparrow 113.46$ & 56.73 & $\uparrow 164.57$ & 153.07 & 0.165 \\
\hline
\end{tabular}

\section{DISCUSSION}

Tooth extraction associated with changes in both vertical and horizontal dimensions of the alveolar bone, more pronounced in the buccal ${ }^{(14)}$.

The resorption process varies greatly amongst individual patients and tooth position and may be affected by several factors such as the presence of infection, previous periodontal disease, the extent of a traumatic injury and the number or the thickness of the bony socket walls. An equilibrium is reached approximately 3-4 months post-extraction, resulting in a bone and soft tissue level that is lower than that of the neighboring teeth as complete regeneration of the socket site never occurs ${ }^{(15)}$.

Alveolar socket preservation techniques have been widely used for clinicians to prevent the loss of bone volume ${ }^{(16)}$. Ridge preservation therapy reduces the marginal bone loss by $.039 \mathrm{~mm}$ compared with unassisted ridge healing ${ }^{17}$.

Therefore, the use of an inexpensive, fast, safe, painless, and with no side effect treatment using simvastatin drug could improve tissue repair.

Simvastatin is a small molecule drug that belongs to the statin group. It is known as coenzyme A reductase inhibitor that is mainly used to decrease serum cholesterol levels and has shown effects on new bone formation through increasing the expression of the BMP-2 gene in bone cells ${ }^{(18)}$. 
Due to serious side effects of systemic administration of statins like liver toxicity, myositis (inflammation of the muscle), and rhabdomyolysis (severe muscle inflammation and damage) local application was used for effective bone regeneration with virtually no side effects. As well as the local application allows an adequate dosage to be delivered to the desired area without relying on systemic administration ${ }^{(19)}$.

In this study, gelatin sponge was used as a carrier, gelatin sponge is a haemostatic material commonly used in surgery, and may be left at the application site, as it is bioresorbable. Its spongy nature makes it potentially suitable as a carrier for drug delivery.

This study aimed to evaluate the the efficacy of simvastatin on bone regeneration for socket preservation after tooth extraction. Twenty dental sockets for patients who were need extraction of lower first molar, the patients were randomly selected and divided into two groups.

Wong and Rabie ${ }^{(20)}$ used simvastatin for parietal bone defects and found 308\% more new bone in defects grafted with simvastatin. The present study showed no infection in both Control and study groups, in which procedure was simple and patients were covered by antibiotics, this in accordance with saifi et $\mathrm{al}^{(21)}$ and Degala et $\mathrm{al}^{(13)}$ which suggests that that simvastatin gelatin sponge is well tolerated by the patients and is safe for local application.

Both group showed a statistically non-significant difference in mean facial edema measurements. Pain assessed by VAS and there was a statistically non-significant difference in mean VAS in the two groups, non steroidal anti inflammatory drug prescribed for five days postoperatively as well as procedure was simple . this in accordance with saifi et $\mathrm{al}^{(21)}$.

In comparison between the two studied groups according to density: After 4 months, there was a statistically significant difference in mean density in the two groups. The study group showed a significant increase in density in the study group than the control group. These results corresponded with those of Chauhan et $\mathrm{al}^{(22)}$, Saifi et $\mathrm{al}^{(21)}$ and Degala et $\mathrm{al}^{(13)}$.
In a comparison between the two studied groups according to width: Immediately, there was a statistically non-significant difference in mean width in the two groups. After 4 months, more reduction of bone width in the control group than the study group and there was a statistically significant difference in mean width in the two groups. This in agree with Sherif et $\mathrm{al}^{(23)}$ which informed the rate of width resorption was less in the simvastatin group than control group in animal rat.

In comparison between the two studied groups according to height: Immediately and after 4 months, more reduction in bone height in the control group than the study group and there was a statistically non-significant difference in mean height in the two groups. This in agree with Yaghobee et $\mathrm{al}^{(24)}$ and Sherif et $\mathrm{al}^{(23)}$.

So the simvastatin induce bone formation as in this study showing a significant increase in density in the simvastatin group than the control group. But cannot preserve alveolar bone height as a statistically non-significant difference in mean height in the two groups.

This is study assessd alveolar bone height, width and density by cone beam $\mathrm{CT}$ immediately after extraction and after four months.

Limitations in this study were small sample size and short follow up time .

\section{CONCLUSION}

1. Findings from this study have demonstrated simvastatin to be a suitable biomaterial for socket preservation.

2. The use of Simvastatin produce significantly more bone compared to gelatin sponge.

3. Local application of simvastatin to bone defects could accelerate bone regeneration

Limitation of this study included: a small sample size and a short follow up time . 


\section{REFERENCES}

1. Bartee, Barry K. Extraction site reconstruction for alveolar ridge preservation Part 1: rationale and materials selection. J Oral Impl. 2001; 187-193 .

2. Darby, I., S. Chen, and R. De Poi. Ridge preservation: what is it and when should it be considered. Aust dent $\mathrm{J}$, 2008; 11-21.

3. Pietrokovski J, Massler M. Alveolar ridge resorption following tooth extraction. J Prost Dent, 1967; 21-27.

4. Shilpa BS, Dhadse PV, Bhongade ML, Puri S, Nandanwar J. Evaluation of effectiveness of platelet-rich fibrin for ridge preservation after a traumatic extraction: A case series. JDMIMSU, 2017; 294.

5. Fairbairn P, Leventis M, Mangham C, Horowitz R. Alveolar Ridge Preservation Using a Novel Synthetic Grafting Material: A Case with Two-Year Follow-Up. Case Rep Dent, 2018.

6. Pandit N, Pandit IK, Malik R, Bali D, Jindal S. Autogenous bone block in the treatment of teeth with hopeless prognosis. Contemp Clin Dent, 2012; 437-442.

7. Kumar G, Narayan B. Morbidity at bone graft donor sites. In: Classic Papers in Orthopedics. Springer, London, 2014; 503-505.

8. Leventis, Minas D., et al. Minimally invasive alveolar ridge preservation utilizing an in situ hardening $\beta$-tricalcium phosphate bone substitute: a multicenter case series. Inter J Dent, 2016; 106-112

9. AI-AQL, Z. S., et al. Molecular mechanisms controlling bone formation during fracture healing and distraction osteogenesis. J Dent Res , 2008; 107-118.

10. Park, Jun-Beom. The use of simvastatin in bone regeneration. Med Oral Patol Oral Cir Bucal, 2009; 485-8

11. . Mansour G, Al Ashwah A, Koura A. Evaluation of simvastatin grafting around immediate dental implants in dogs. Impl Dent, 2014; 195-199.

12. Liu, Chang, Zhe Wu, and Hong-Chen Sun. The effect of simvastatin on mRNA expression of transforming growth factor- $\beta 1$, bone morphogenetic protein- 2 and vascular endothelial growth factor in tooth extraction socket. Inter $\mathbf{J}$ Oral Scie, 2009;90-98.

13. Degala S, Bathija NA. Evaluation of the Efficacy of Sim- vastatin in Bone Regeneration after Surgical Removal of Bilaterally Impacted Third Molars - A Split-Mouth Randomized Clinical Trial. J Oral Maxi S, 2018; 1847-1858

14. Park, Su-Hyun, et al. Clinical benefits of ridge preservation for implant placement compared to natural healing in maxillary teeth: A retrospective study. Journal of Clinical Periodontology, 2020, 47.3: 382-391

15. Macbeth, Neil, et al. Hard and soft tissue changes following alveolar ridge preservation: a systematic review. Clinical oral implants research, 2017, 28.8: 982-1004

16. Fee, L. "Socket preservation." British Dental Journal 222.8 (2017): 579-582

17. Avila-Ortiz, G., et al. "Effect of alveolar ridge preservation after tooth extraction: a systematic review and metaanalysis." Journal of dental research 93.10 (2014): 950958

18. Martin, Victor; Bettencourt, Ana. Bone regeneration: Biomaterials as local delivery systems with improved osteoinductive properties. Materials Science and Engineering: C, 2018, 82: 363-371.

19. Shah, Sarita R., et al. "Novel applications of statins for bone regeneration." National science review 2.1 (2015): 85-99

20. Wong, Ricky WK, and A. Bakr M. Rabie. "Early healing pattern of statin-induced osteogenesis." British Journal of Oral and Maxillofacial Surgery 43.1 (2005): 46-50.

21. Saifi AM, Giraddi GB, Ahmed N. Healing of extraction socket following local application of simvastatin: A splitmouth prospective study. JOBCR. 2017;106-112.

22. Chauhan, Anil Singh, Anisha Maria, and Anil Managutti. "Efficacy of simvastatin in bone regeneration after surgical removal of mandibular third molars: A clinical pilot study." Journal of maxillofacial and oral surgery 14.3 (2015): 578-585

23. Sherif, Youmna M., et al. "Evaluation of local administration of simvastatin on height and width of the healing extraction socket in rat mandible." Alexandria Dental Journal 41.3 (2016): 283-286

24. Yaghobee, Siamak, et al. "Radiographic comparison of bovine bone substitute alone versus bovine bone substitute and simvastatin for human maxillary sinus augmentation." Journal of Dentistry (Tehran, Iran) 15.1 (2018): 20 